\title{
Flora of aquatic and wetland habitats on Jeju Island
}

\author{
Dae-Hyun Kang, Eun-Young Yim ${ }^{1}$ and Myung-Ok Moon ${ }^{1 *}$ \\ Department of Life Sciences, Hallym University, Chuncheon 200-702, Korea \\ ${ }^{1}$ Jeju National University Research Institute for Basic Sciences, Jeju 690-756, Korea \\ (Received 15 December 2014; Accepted 11 February 2015)
}

\section{제주도의 수생 및 습생 식물상 \\ 강대현, 임은영', 문명옥 ${ }^{*}$ \\ 한림대학교 생명과학과, ${ }^{1}$ 제주대학교 기초과학연구소}

\begin{abstract}
This study presents a comprehensive account of the flora of hydrophytes and hygrophytes on Jeju Island. This approach aims to contribute to fundamental information about the conservation of plant diversity in wetlands. Field surveys were carried out from May of 2010 to September of 2014 in various types of wetlands on Jeju Island. A total of 189 taxa, including 52 families, 98 genera, 181 species, 6 varieties, 2 forma and 189 taxa, were found. Among them, 99 taxa (38 families, 60 genera, 96 species and 3 varieties) were hydrophytes and 90 taxa (23 families, 45 genera, 85 species, 3 varieties and 2 forma) were hygrophytes. In addition, Eleocharis $\times$ yezoensis H. Hara (Cyperaceae) was newly added to the flora of Korea. The protected wild plants designated by the Ministry of the Environment were 5 taxa, including Brasenia schreberi J. F. Gmel. and Dysophylla yatabeana Makino. The endangered species found included one Critically Endangered Species (i.e., Mankyua chejuense B.-Y. Sun, M. H. Kim \& C. H. Kim), 5 Endangered Species (e.g., Lysimachia leucantha Miq.) and 7 Vulnerable Species (e.g., Tillaea aquatica L.). The floristic regional indicator plants found in this area were 44 taxa comprising 10 taxa of grade V, 7 taxa grade IV, 15 taxa of grade III, 5 taxa of grade II, and 7 taxa of grade I. The identified naturalized plants were 10 taxa; 8 families, 8 genera, 9 species and 1 variety. In the wetlands on Jeju Island, high plant species diversity was shown, and a number of rare plants and phytogeographically important plants were found. For these reasons, we consider that the wetlands on Jeju Island are very important areas from a botanical point of view. It is necessary to establish specific protection and maintenance policies in an effort to conserve these wetlands and species.
\end{abstract}

Keywords: vascular plant flora, hydrophyte, hygrophyte, unrecorded sedge, Jeju province

적 요: 본 연구는 제주도에 분포하는 수생 및 습생 식물의 식물상을 규명하고, 습지환경의 식물종다양성을 보존 하기 위한 기초자료를 확보하고자 수행하였다. 야외 조사는 제주도 전 지역을 대상으로 2010년 5월부터 2014년 9 월에 걸쳐 이루어졌다. 본 식물상 연구를 통해 확인된 습지식물은 총 52과 98속 181종 6변종 2품종 189 분류군이 었다. 이 중 총 38 과 60 속 96종 3변종 99분류군이 수생식물로, 23과 45속 85종 3변종 2품종 90분류군이 습생식물 로 나타났다. 또한 사초과 식물인 Eleocharis $\times$ yezoensis H. Hara를 한국미기록식물로 보고하였다. 조사된 식물 중 환경부지정보호야생식물은 순채, 전주물꼬리풀 등 5 분류군이 분포하는 것으로 조사되었다. 멸종위기종은 위급종 이 제주고사리삼 1 분류군, 위기종이 물까치수염 등 5 분류군, 취약종이 대구돌나물 등 7 분류군으로 나타났다. 식 물구계학적 특정식물로는 $\mathrm{V}$ 등급이 10 분류군, IV등급이 7 분류군, III등급이 15 분류군, II등급이 5 분류군, I등급이 7 분류군으로 총 44 분류군이 확인되었다. 귀화식물은 총 8 과 9속 9종 1 변종 10 분류군으로 나타났다. 제주도의 습지

\footnotetext{
*Author for correspondence: taxamo@empas.com
}

http://www.pltaxa.or.kr

Copyright (C) 2015 the Korean Society of Plant Taxonomists 
는 식물종다양성이 매우 높고, 희귀식물 및 식물지리학적으로 중요한 식물 등이 다수 분포하여 식물학적 가치가 매우 높은 것으로 판단된다. 따라서 습지 및 종의 보존을 위한 구체적인 보호 및 관리 체계의 수립이 요구된다.

주요어: 관속식물상, 수생식물, 습생식물, 미기록 사초과 식물, 제주지역

습지는 국가와 단체마다 다르게 정의되어 있는데 우리 나라의 습지보전법 제 2 조에 따르면 습지는 담수, 기수 또 는 염수가 영구적 또는 일시적으로 그 표면을 덮고 있는 지역으로서 내륙습지 및 연안습지를 말한다(Ministry of environment, 2014). 이러한 환경에서 자라는 식물을 습지 식물이라 하며 그 중에서도 수중 생활에 적응하여 그들의 생활사 중 어느 한 시기를 수중에서 생육하게 되는 종류 들을 수생식물이라 한다. 또한, 습지 환경에 적응하였으 나 수생식물의 범주에 포함되지 않는 무리를 습생식물이 라고 한다. 그러나 습지에서 생육하는 식물인 습지식물에 서 수생식물을 구별하기는 어려운 것으로 여겨진다(Choi, 1985). Sculthorpe (1967)는 수생식물의 범위를 유관속이 있 는 초본성인 수생식물로 한정하기도 하였다. 그리고 습지 에 뿌리를 내리는 분류군들로, 주로 물가의 가장자리에 생 육하며 뿌리 정도가 물에 잠기는 식물군을 정수성 수생식 물(emergent hydrophytes), 수면에 잎이 뜨는 부엽성 수생식 물(floating-leaved hydrophytes), 영양기관이 물에 잠겨 있는 침 수성 수생식물(submerged hydrophytes)로 구분하였다. 또한 땅속에 뿌리를 내리지 않고 수중이나 수면에 떠다니며 생 활하는 식물군을 부유성 수생식물(free-floating hydrophytes) 로 구분하였다. 한편 Koo (2002)는 습지의 유형구분에 관 한 연구에서 습지 식생을 절대습지식생 $(\mathrm{OBL})$, 상대적습 지식생 $(\mathrm{FACW})$, 중성식생 $(\mathrm{FAC})$, 습성내륙식생(FACU), 내 륙식생(UPL)등 크게 5 개의 범주로 구분 한 바 있다. 절대 습지식생 $(\mathrm{OBL})$ 은 특정 습지 환경에서만 생존하는 식생 으로 그 빈도가 $99 \%$ 이상인 경우를, 상대적습지식생 $(\mathrm{FACW})$ 는 습지환경과 내륙환경에 모두 생장이 가능하나 67\%-99\% 빈도로 습지환경에 발생하는 경우를 말한다. 또 한 중성식생 $(\mathrm{FAC})$ 는 습지조건이나 건조상태에서도 비슷 하게 발견되는 경우로 $34 \%-66 \%$ 빈도로 습지에 출현하는 경우를 말한다. 습성내륙식생(FACU)과 내륙식생은(UPL) 은 각각 주로 습지에 나타나지만, 습지에서도 발견되는 경우(1-33\%)와 내륙환경에서만 출현하는 식생을 $(99 \%$ 이 상) 말하며 보통 육상식물을 말한다.

제주도는 면적이 $1,849.2 \mathrm{~km}^{2}$ 에 이르는 국내에서는 가 장 넓은 섬이다. 연평균 강수량은 제주시가 $1,584.9 \mathrm{~mm}$, 서 귀포시가 $2,393.3 \mathrm{~mm}$ 이고, 평균기온은 제주시가 $15.6^{\circ} \mathrm{C}$, 서귀포시가 $16.9^{\circ} \mathrm{C}$ 로서 온대기후에 해당한다. 지질학적 으로는 퇴적암층과 현무암, 조면질안산암, 조면암 등의 화산암류와 기생화산에서 분출한 화산쇄설암 등으로 구 성되어 있으며, 일부 지역의 점사질 토양을 제외하면 대 부분이 흑갈색의 화산회토로 덮여 있다(Jeju Special SelfGoverning Province, 2014). 제주도의 하천은 대부분 건천이
며, 일부 지역 불투수층에 형성된 습지와 고산습지, 저수지 와 인공수로, 인가 혹은 도로변에 만들어지거나 정비가 된 인공습지, 해안선을 따라 형성된 해양 및 연안습지 등 다양 한 형태의 습지들이 분포하고 있는 것으로 알려져 있다.

제주도에 분포하는 수생식물에 관한 연구는 Oh (1974)의 물별이끼를 제주분포 미기록 식물로 보고하고, 제주도의 26 개 습지에서 25 과 38 속 55종 총 55 분류군의 수생식물을 정리한 것이 최초이다. 한편 Song (2005)은 식물도해와 자 생지 정보 등을 제시하며 제주도에 분포하는 42과 63속 105 종 총 105 분류군의 수생식물을 정리하여 제주 자생 수생식 물도감을 출판하였다. 최근에는 Zhin (2008)이 제주시 지역 29 개소의 습지를 대상으로 수생 및 습생식물을 조사하여 30 과 45속 71종 총 71 분류군의 수생식물이 분포하고 있다 고 보고하였다. 또한, $\operatorname{Lim}(2010)$ 이 한국의 수생식물 분포특 성 연구의 일원으로 25 개소에서 28 과 32 속 45 종 총 45 분류 군의 수생식물을 조사하고, 과거 문헌을 정리하여 총 92분 류군을 제주도에 분포하는 수생식물로 정리한 바 있다.

그러나 제주도 습지의 식물상에 관한 연구는 대부분 비 전문가가 포함된 지자체와 민간단체에 의해 수행되거나, 일부 보존 가치가 높은 유형의 습지에 관한 반복적인 조사 가 대부분이다. 이는 습지식물상이 특정 습지에 한정되는 한계를 가지고 왔다. 제주도 전 지역을 대상으로 한 연구 또한, 종의 목록만 제시된 경우가 많았고, 유사분류군 간의 혼동이 있어도 확증표본이 제시되지 않아 비교연구가 어 렵고 추측만이 가능하였다. 또한 습생식물과 수생식물의 특성과 범주에 관해서도 일관된 기준이 있는 것이 아니라 연구자들의 이견이 있었던 것으로 파악되어 습지식물상 에 대한 연구 간에 절대적인 비교가 힘든 것으로 생각된다.

따라서 본 연구에서는 확증 표본 인용과 충분한 분류학 적 검토를 통해 제주도 습지에 분포하는 관속식물의 현황 을 파악하고 이를 수생식물과 습생식물로 구분하여 정리 함으로써 식물상을 규명하고자 하였다. 더 나아가 습지라 는 특수한 환경에 적응한 식물의 종 다양성을 보존하기 위한 기초자료를 확보하고자 수행하였다.

\section{재료 및 방법}

제주도 전 지역의 습지에 분포하는 관속식물을 대상으 로 문헌 조사, 야외 조사 및 표본 조사를 종합하여 식물상 목록을 작성하였다.

문헌 조사는 Oh (1974), Zhin (2008), Lim (2010), Song (2005) 등을 검토하여 수행하였다. 야외 조사는 2010년 5 월부터 2014년 9월까지 70여 차례에 걸쳐 수행되었고, 습 
지식물을 채집한 후 국내외 문헌을 참고하여 동정 및 분류 하였으며(Ohtaki and Ishido, 1980; Yasuro, 1994; Lee, 1996, $2003,2006)$, 확증표본으로 제작하여 제주대학교 표본관 (JNUB)에 보관하였다. 또한, 표본 조사는 제주대학교 표 본관(JNUB)과 난대 아열대산림연구소 표본관(WTFRC)에 수장된 습지식물 표본을 연구의 재료로 사용하여 수행하 였다. 습지에 우연히 이입된 것으로 판단되는 식물이나 습지에 생육하고 있으나 습지 이외의 지역에서도 쉽게 관 찰되는 식물들은 식물상에서 제외하였다.

조사된 습지식물은 수생식물과 습생식물로 구분하여 정리하였다. 수생식물의 정의와 범주는 Muensher (1944) 와 Sculthorpe (1967)의 견해를 따라 습지에서 자라고 그 중 에서도 수중 생활에 적응하여 그들의 생활사 중 어느 한 시기를 수중에서 생육하게 되는 종류들을 수생식물로 구 분하였다. 그러나 실제 모든 분류군에 이 정의를 적용하 는 것은 무리가 있어 그 대안으로 선행 연구인 Ohtaki and Ishido (1980), Choi (1985), Yasuro (1994), Lim (2010)이 수 생식물로 판단한 분류군을 수생식물로 정하였다. 또한, 완전히 수생 환경에 적응한 분류군으로 판단되면, 선행연 구에 포함되지 않았더라도 수생식물로 판단하여 포함했 다. 그리고 Sculthorpe(1967)의 생활형에 따라 수생식물을 다시 정수성 수생식물, 부엽성 수생식물, 침수성 수생식 물, 부유성 수생식물로 나누어 파악하였다.

습생식물(Hygrophytes)은 습지식물로 파악되었으나 수 생식물에서 제외되는 식물로 Koo (2002)의 습지 식생의 구분에서 상대적습지식생(FACW), 중성식생(FAC)에 포 함되는 식물로 판단하였다.

또한, 이상의 결과를 근거로 멸종위기식물, 식물구 계학적 특정식물종, 귀화식물 등을 파악하여 목록을 작성하였다(Lee, 2003; Park, 2009; Lim, 2010; Ministry of Environment, 2012a, b; National Institute of Biological Resources, 2012). 분류군의 배열, 학명 및 국명의 채택은 Park (2007)을 기준으로 하되, 포함되지 않은 분류군과 근 래에 발표되었거나 분류학적 검토가 이루어진 분류군에 대해서는 Lee (1996), Jung (2010) 등도 참고하였다. 한편, 본 조사를 통해 새롭게 확인된 한국미기록식물을 자세히 기재하고 근연분류군과 비교하였다.

\section{결과 및 고찰}

\section{식물상}

제주도내에 233개소의 습지를 조사한 결과, 습지식물 은 총 52과 98속 181종 6변종 2품종 189분류군으로 나타났 다. 이 중 양치식물은 4 과 4 속 4 종 4 분류군 $(2.11 \%)$, 피자식 물 중 단자엽식물이 19과 49속 106종 3변종 2품종 111분류 군 $(58.73 \%)$, 쌍자엽식물이 29과 45속 71종 3변종 74분류군 (39.15\%)으로 조사되었다(Appendix 1). 한편 수생식물은 총 38 과 60 속 96 종 3 변종 99 분류군이었으며, 습생식물은
총 23 과 45 속 85 종 3 변종 2 품종 90 분류군으로 조사되었다.

\section{1) 수생식물}

제주도에 분포하는 습지식물 중 수생식물의 범주에 속 하는 식물은 총 38과 60속 96종 3변종 99분류군으로 나타 났다. 양치식물은 2과 2속 2종 2분류군(2.02\%), 피자식물 중 단자엽식물이 18 과 36 속 66 종 2 변종 68 분류군 $(68.68 \%)$, 쌍자엽식물이 18과 22속 28종 1변종 29분류군(29.29\%)이 조사되었다(Table 1). 또한, 선행연구로서 수생식물로 파 악된 분류군 이외에 현삼과의 물꼬리풀과 전주물꼬리풀 은 어린 개체들이 수중에서 생육하는 것이 확인되었으며 성숙한 개체로 자란 후에도 뿌리 등이 물에 잠겨 생육하 는 것을 확인하였다. 따라서 Muensher (1944)와 Sculthorpe (1967)이 수생식물로 정의한 범주에 포함되는 것으로 판 단하여 수생식물에 포함하였다.

수생식물에서는 Cyperaceae(사초과)가 19분류군, $19.19 \%$ 로 가장 많은 분류군을 포함하고 있었으며 그 다음으로 Potamogetonaceae(가래과)가 7분류군으로 7.07\%였고 Scrophulariaceae(현삼과), Alismataceae(택사과), Eriocaulaceae(곡정 초과), Poaceae(벼과)가 각각 6분류군으로 $6.06 \%$, Hydrocharitaceae(자라풀과)가 4분류군으로 $4.04 \%$, Menyanthaceae (조름나물과), Najadaceae(나자스말과), Lemnaceae(개구리 밥과)가 각각 3 분류군으로 $3.03 \%$ 로 나타났다(Fig. 1).

육상 생태계와 습지라는 특이적인 환경에 모두 적응한 Cyperaceae(사초과) 식물들이 많이 조사 되었으며 주로 수 생식물로 구성되어 있는 Potamogetonaceae(가래과), Alismataceae(택사과), Hydrocharitaceae(자라풀과) 등이 높은

Table 1. The number of hydrophyte taxa in Jeju Island.

\begin{tabular}{cccccc}
\hline \hline Taxa & Families & Genera & Species & Varieties & Total \\
\hline Pteridophyte & 2 & 2 & 2 & 0 & 2 \\
Angiospermae & 36 & 58 & 94 & 3 & 97 \\
Monocotyleons & 18 & 36 & 66 & 2 & 68 \\
Dicotyleons & 18 & 22 & 28 & 1 & 29 \\
\hline Total & 38 & 60 & 96 & 3 & 99 \\
\hline
\end{tabular}

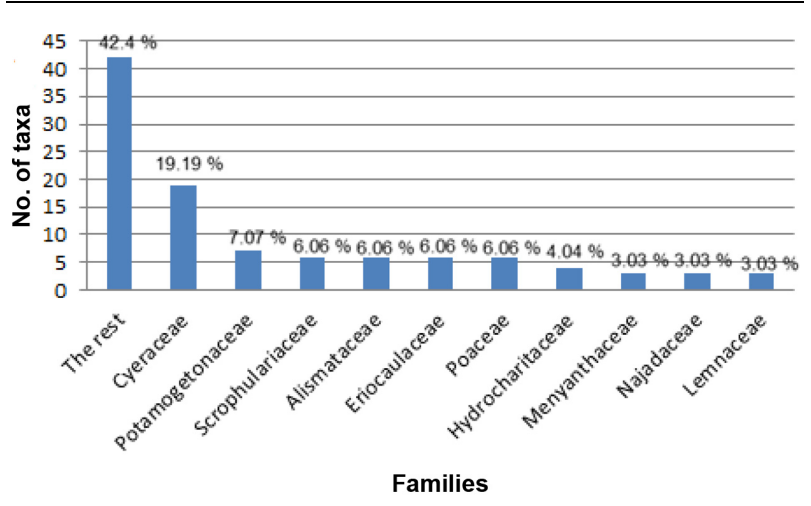

Fig. 1. The proportion of hydrophyte taxa in major families distributed in Jeju Island. 
빈도로 출현 하였다.

수생식물을 생육형태에 따라 구분한 결과, 정수성 수생 식물(emergent hydrophytes)이 66분류군(66.66\%)으로 가장 많 은 유형으로 나타났으며 침수성 수생식물(submerged hydrophytes)이 16분류군(16.16\%), 부엽성 수생식물(floatingleaved hydrophytes)이 10 분류군(10.10\%), 부유성 수생식물 (free-floating hydrophytes)이 7분류군(7.14\%) 순으로 조사 되었다(Table 2).

\section{2) 습생식물}

제주도에 분포하는 습생식물은 총 23 과 45 속 85 종 3 변 종 2 품종 90 분류군이었다. 양치식물은 2 과 2 속 2 종 2 분류 군(2.22\%), 피자식물 중 단자엽식물이 4과 15 속 40 종 1 변 종 2품종 43분류군(47.78\%), 쌍자엽식물이 17과 28속 43종 2변종 45분류군(50\%)으로 나타났다(Table 3).

이 중 Cyperaceae(사초과)가 24분류군, $26.67 \%$ 로 가장 많 은 분류군을 포함하고 있었으며 Poaceae(벼과)가 11 분류 군으로 $12.22 \%$, Polygonaceae(마디풀과)가 8 분류군으로 $8.89 \%$, Juncaceae(골풀과), Asteraceae(국화과)가 각각 7 분 류군으로 $7.78 \%$, Ranunculaceae(미나리아재비과)가 5 분류 군으로 $5.56 \%$, Lamiaceae(꿀풀과), Apiaceae(미나리과)가 각각 4 분류군으로 $4.44 \%$, Scrophulariaceae(현삼과)가 3 분 류군으로 $3.33 \%$ 로 나타났다(Fig. 2.). 수생식물의 경우와 마찬가지로 Cyperaceae(사초과)의 비율이 가장 높았으며, Poaceae(벼과)의 비율이 높게 나타났다.

수생식물을 제외한 습생식물 대부분의 분류군은 수면 의 변동이 큰 습지 가장자리와 육지생태계의 경계 부분에 서 생육하였다. 또한, 습지에서도 쉽게 관찰이 되는 여뀌, 며 느리밑씻개, 며느리배꼽, 수영, 환삼덩굴 등의 다수의 종은 일시적으로, 습지 및 습지주변에 분포하거나 육상생태계의

Table 2. Life form spectrum of hydrophytes.

\begin{tabular}{lcc}
\hline \hline Life form & Taxa & Percent (\%) \\
\hline Hydorphytes attached to the substrate & & \\
Emergent hydrophytes & 66 & 66.66 \\
Submerged hydrophytes & 16 & 16.16 \\
Floating-leaved hydrophytes & 10 & 10.10 \\
Free-floating hydrophytes & 7 & 7.07 \\
\hline Total & 98 & 100.00 \\
\hline
\end{tabular}

Table 3. The number of hygrophyte taxa in Jeju Island.

\begin{tabular}{|c|c|c|c|c|c|c|}
\hline Taxa & Families & Genera & Species & Varieties & Forma & Total \\
\hline Pteridophyte & 2 & 2 & 2 & 0 & 0 & 2 \\
\hline Angiospermae & 21 & 43 & 83 & 3 & 2 & 88 \\
\hline Monocotyleons & 4 & 15 & 40 & 1 & 2 & 43 \\
\hline Dicotyleons & 17 & 28 & 43 & 2 & 0 & 45 \\
\hline Total & 23 & 45 & 85 & 3 & 2 & 90 \\
\hline
\end{tabular}

전이지대에 분포하여 습생식물로 판단하지 않고 식물상 목 록에서 제외하였다. 제외된 분류군들은 육상식물로 습지에 적응한 식물이라고 볼 수 없으며 습지를 다른 육상생태계 와 구분할 수 있는 습생식물이라고 판단되지 않는다. 또한, 위의 분류군은 Koo (2002)에 따라 습성내륙식생(FACU), 내 륙식생(UPL)에 포함되며 육상식물이라고 할 수 있다.

\section{한국 미기록 식물}

본 연구를 통하여 제주시 애월읍 유수암리에 위치한 숨 은물뱅디 습지에서 사초과의 미기록식물인 Eleocharis $\times$ yezoensis $\mathrm{H}$. Hara가 분포함이 확인되어 한국미기록식물로 기재하였다.

\section{분류군의 기재}

Eleocharis $\times$ yezoensis H. Hara, Bot. Mag. (Tokyo) 52: 396 . 1938.

정수성 수생식물. 식물체 크기 $30-35 \mathrm{~cm}$. 줄기 총생, 세 로로 약간 홈이 있으며 4-5 각; 길이 12-29 cm, 너비 $1 \mathrm{~mm}$; 기부의 잎싸개는 붉으며 정단이 비스듬히 잘림; 길이 $16-$ $55 \mathrm{~mm}$. 꼬마이삭 붉은색, 선형 또는 피침형; 길이 6$15 \mathrm{~mm}$; 두께 1.5-3.5 mm. 비늘조각 난형 혹은 타원형, 적 갈색, 등 부분은 담록색, 길이 $1.5-2.5 \mathrm{~mm}$, 너비 $1.3-$ $1.5 \mathrm{~mm}$; 가장자리는 백색의 막질. 수과 도란형, 눌린 삼각 형, 둔함, 갈색, 길이 $1.3 \mathrm{~mm}$, 너비 $0.7 \mathrm{~mm}$. 암술대 밑부분 큰 원뿔 삼각형, 길이 $0.8 \mathrm{~mm}$, 폭 $0.5 \mathrm{~mm}$. 암술머리는 3 갈 래, 길이 $1 \mathrm{~mm}$. 너비 $0.9 \mathrm{~mm}$. 화피 조각 6 개, 강모 모양, 길 이 2.1-2.7 mm. 화피 조각에 거꾸로 향한 가시가 있음, 길 이 $0.15 \mathrm{~mm}-0.25 \mathrm{~mm}$.

국명: 긴바늘골(Gin-ba-neul-gol)

분포: 일본(홋카이도), 한국(제주도)

관찰표본: KOREA - Jeju Special Self-Governing Province, Jeju-si, Aewol-eup, Yusuam-ri, Sumeunmulbengdui, 15 Aug. 2010, D.H. Kang \& S.H. Kang coll. no. 962 (4 sheets) (JUNB)

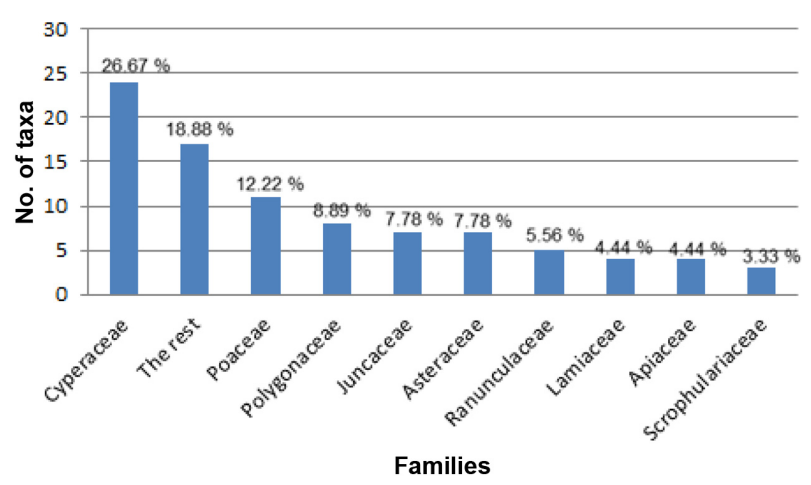

Fig. 2. The proportion of hygrophyte taxa in major families distributed in Jeju Island. 
본 종은 일본특산의 신종으로 기재된 바 있으나(Hara, 1938), 좀네모골(Eleocharis wichurai Boeck.)과 바늘골 [Eleocharis congesta var. japonica (Miq.) T. Koyama]의 잡종 임이 규명되었다(Kitamura et al., 1964). 부모종인 좀네모 골(Eleocharis wichurai Boeck.)과는 화피조각이 깃털 모양이 아닌 강모 모양이라는 점에서, 바늘골[Eleocharis congesta var. japonica (Miq.) T. Koyama]과는 암술대 밑부분의 너비 가 $1 / 2$ 이상인 점에서 구별된다. 유사분류군인 참바늘골 [Eleocharis attenuata for. laeviseta (Nakai) Hara]은 꼬마이삭 이 난형이지만 본 종은 꼬마이삭이 선형 혹은 피침형이다 (Fig. 3). 숨은물뱅디의 습한 초지에서 드물게 자라며, 속 내 다른 분류군에 비해 고마이삭이 선형 혹은 피침형으로 긴 점에 착안하여 국명을 '긴바늘골'로 칭하였다.

\section{국내에 분포하는 긴네모골(Eleocharis $\times$ yezoensis H. Hara)과 근연분류군의 검색표}

1. 암술머리 2; 수과의 단면은 3 면이 볼록하다.

2. 암술대 밑부분은 반타원형이며 수과와 너비가 비슷 하다.

3. 화피 조각 5 .

……………. Eleocharis kamtschatica 올방개아재비

3. 화피가 없다.

Eleocharis kamtschatica f. reducta 무화피올방개아재비

2. 암술대 밑부분은 원추형이며 수과의 너비의 $1 / 2$ 정도 이다.

4. 화피 조각 5 , 깃털 모양.

... Eleocharis mamillata var. cyclocarpa 물꼬챙이골 4. 화피 조각 4 , 강모 모양.

Eleocharis equisetiformis 까락골

1. 암술머리 3; 수과의 단면은 양면이 볼록하거나 3 면중 2면이 더 볼록하다.

5. 화피 조각은 깃털 모양.

Eleocharis wichurai 좀네모골

5. 화피 조각은 강모 모양.

6. 줄기의 단면은 3 각형.

- Eleocharis acicularis f. longiseta 쇠털골

6. 줄기의 단면은 원형 혹은 4-5각형.

7. 암술대 밑부분의 너비가 수과의 너비의 $1 / 3$ 정도.

8. 비늘조각의 윗부분이 뾰족하고, 화피 조각의 길 이가 암술대 밑부분보다 길다.

- Eleocharis congesta var. japonica 바늘골

8. 비늘조각의 윗부분이 둔하고, 화피 조각의 길이 가 암술대 밑부분보다 짧다.

….. Eleocharis congesta var. thermalis 쇠바늘골

7. 암술대 밑부분의 너비가 수과의 너비의 $1 / 2$ 이상.

9. 꼬마이삭은 난형.

....... Eleocharis attenuata for. laeviseta 참바늘골 9. 꼬마이삭은 선형 혹은 피침형.
Eleocharis $\times$ yezoensis 긴바늘골

\section{멸종위기식물}

제주도의 습지에는 제주고사리삼, 삼백초, 순채, 전주물 꼬리풀, 자주땅귀개 등 5 분류군의 환경부지정보호야생식 물이 분포하는 것으로 나타났다. 또한, 한국적색목록에 기 록된 멸종위기식물은 위급종(Critically Endangered, $\mathrm{CR}$ )에 제주고사리삼 1 분류군, 위기종(Endangered, $\mathrm{EN}$ )이 물까 치수염, 삼백초, 솜아마존, 전주물꼬리풀, 애기어리연 등 5 분류군, 취약종(Vulnerable, $\mathrm{VU})$ 이 대구돌나물, 둥근잎 택사, 소엽풀, 솔잎가래, 순채, 올챙이자리, 자주땅귀개 등 7 분류군이 분포하는 것으로 조사되었다(Table 4). 제주 고사리삼은 동북부지역의 곶자왈 지대에 형성된 소택지 에 한정적으로 분포하고 있으며 순채 역시 동북부지역 목장 지대의 용암암반 위에 형성된 습지에 비교적 많은 개체가 분포하고 있었다. 삼백초는 서남부 지역의 저수 지 근처와 오름 분화구 주변에서 소수의 개체가 자라는

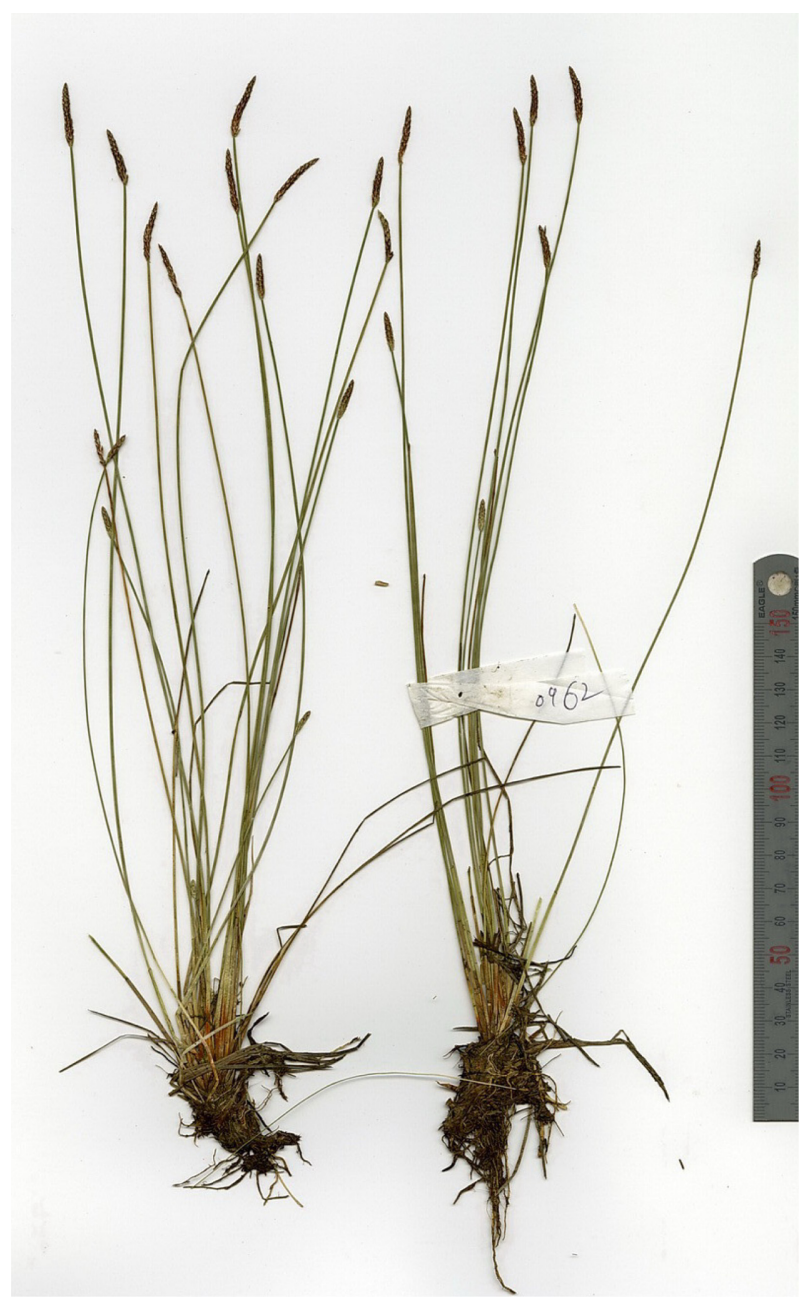

Fig. 3. Eleocharis $\times$ yezoensis $\mathrm{H}$. Hara collected from Sumeunmulbengdui, Jeju, Korea. 
Table 4. The list of threatened plants and their categories.

\begin{tabular}{|c|c|c|c|}
\hline Scientific Name & Korean Name & 1 & 2 \\
\hline Mankyua chejuense B.-Y. Sun, M. H. Kim \& C. H. Kim & 제주고사리삼 & II & $\mathrm{CR}$ \\
\hline Lysimachia leucantha Miq. & 물까치수염 & & $\mathrm{EN}$ \\
\hline Saururus chinensis (Lour.) Baill. & 삼백초 & II & $\mathrm{EN}$ \\
\hline Cynanchum amplexicaule (Siebold \& Zucc.) Hemsl. & 솜아마존 & & $\mathrm{EN}$ \\
\hline Dysophylla yatabeana Makino & 전주물꼬리풀 & II & $\mathrm{EN}$ \\
\hline Nymphoides coreana (H. Lev.) H. Hara & 애기어리연 & & EN \\
\hline Tillaea aquatica $\mathrm{L}$. & 대구돌나물 & & VU \\
\hline Caldesia parnassifolia (Bassi ex L.) Parl. & 둥근잎택사 & & VU \\
\hline Limnophila aromatica (Lam.) Merr. & 소엽풀 & & VU \\
\hline Potamogeton pectinatus L. & 솔잎가래 & & VU \\
\hline Brasenia schreberi J. F. Gmel. & 순채 & II & $\mathrm{VU}$ \\
\hline Blyxa aubertii Rich. & 올챙이자리 & & $\mathrm{VU}$ \\
\hline Utricularia yakusimensis Masam. & 자주땅귀개 & II & VU \\
\hline
\end{tabular}

1 : Ministry of Environment (2012b), 2 : National Institute of Biological Resources (2012)

Table 5. The list of the floristic regional indicator plants.

\begin{tabular}{|c|c|c|}
\hline Grade & Scientific Name & Korean Name \\
\hline \multirow[t]{10}{*}{ V } & Mankyua chejuense B.-Y. Sun, M. H. Kim \& C. H. Kim & 제주고사리삼 \\
\hline & Saururus chinensis (Lour.) Baill. & 삼백초 \\
\hline & Brasenia schreberi J. F. Gmel. & 순채 \\
\hline & Tillaea aquatica $\mathrm{L}$. & 대구돌나물 \\
\hline & Nymphoides coreana (H. Lev.) H. Hara & 애기어리연 \\
\hline & Dysophylla stellata (Lour.) Benth. in Wall. & 물꼬리풀 \\
\hline & Dysophylla yatabeana Makino & 전주물꼬리풀 \\
\hline & Utricularia yakusimensis Masam. & 자주땅귀개 \\
\hline & Hydrocharis dubia (Blume) Backer & 자라풀 \\
\hline & Sparganium erectum $\mathrm{L}$. & 흑삼릉 \\
\hline \multirow[t]{7}{*}{ IV } & Cyclosorus interruptus (Willd.) H. Ito & 검은별고사리 \\
\hline & Triadenum breviflorum (Wall. ex Dyer) Y. Kimura & 흰꽃물고추나물 \\
\hline & Penthorum chinense Pursh & 낙지다리 \\
\hline & Hygrophila salicifolia (Vahl) Nees in Wall. & 물잎풀 \\
\hline & Adenostemma lavenia (L.) Kuntze & 물머위 \\
\hline & Cladium chinense Nees & 층층고랭이 \\
\hline & Sparganium fallax Graebn. & 남흑삼릉 \\
\hline \multirow[t]{6}{*}{ III } & Polygonum taquetii $\mathrm{H}$. Lev. & 겨이삭여뀌 \\
\hline & Triadenum japonicum (Blume) Makino & 물고추나물 \\
\hline & Lysimachia leucantha Miq. & 물까치수염 \\
\hline & Ludwigia ovalis Miq. & 눈여뀌바늘 \\
\hline & Cynanchum amplexicaule (Siebold \& Zucc.) Hemsl. & 솜아마존 \\
\hline & Cynanchum nipponicum Matsum. & 덩굴박주가리 \\
\hline
\end{tabular}


Table 5. Continued.

\begin{tabular}{|c|c|c|}
\hline Grade & Scientific Name & Korean Name \\
\hline \multirow[t]{9}{*}{ III } & Limnophila aromatica (Lam.) Merr. & 소엽풀 \\
\hline & Limnophila sessiliflora (Vahl) Blume & 구와말 \\
\hline & Alisma orientale (Sam.) Juz. & 질경이택사 \\
\hline & Potamogeton pectinatus L. & 솔잎가래 \\
\hline & Potamogeton maackianus A. Benn. & 새우가래 \\
\hline & Carex maculata Boott & 무늬사초 \\
\hline & Carex phacota Spreng. & 쥐방울사초 \\
\hline & Glyceria acutiflora Torr. & 육절보리풀 \\
\hline & Polypogon monspeliensis (L.) Desf. & 갯쇠돌피 \\
\hline \multirow[t]{5}{*}{ II } & Nymphoides indica (L.) Kuntze & 어리연 \\
\hline & Scutellaria dependens Maxim. & 애기골무꽃 \\
\hline & Ottelia alismoides (L.) Pers. & 물질경이 \\
\hline & Acorus gramineus Aiton & 석창포 \\
\hline & Iris ensata var. spontanea (Makino) Nakai & 꽃창포 \\
\hline \multirow[t]{7}{*}{$\mathrm{I}$} & Elatine triandra Schkuhr & 물별 \\
\hline & Actinostemma lobatum (Maxim.) Maxim. in Franch. \& Sav. & 뚜껑덩굴 \\
\hline & Nymphoides peltata (S. G. Gmel.) Kuntze & 노랑어리연 \\
\hline & Sagittaria aginashi Makino & 보풀 \\
\hline & Potamogeton cristatus Regel \& Maack & 가는가래 \\
\hline & Ruppia maritima $\mathrm{L}$. & 줄말 \\
\hline & Phacelurus latifolius (Steud.) Ohwi & 모새달 \\
\hline
\end{tabular}

것을 확인하였으며 전주물꼬리풀은 동부지역의 소로 주 변의 습지에 매우 한정적으로 분포하고 있었다. 자주땅 귀개는 고지대의 초지 습지에서만 확인되었으며 큰 군락 을 이루며 자라고 있었다. 적색목록 위기종(Endangered, $\mathrm{EN})$ 인 물까치수염, 솜아마존, 애기어리연은 주로 동부지 역 습지에 소수의 개체가 산발적으로 자생하고 있었다. 취약종(Vulnerable, VU)인 대구돌나물, 소엽풀, 솔잎가래, 올챙이자리는 각 1 개소의 습지에서 분포가 확인되었고, 둥근잎택사는 동부지역의 일부 습지에 분포하고 있었다.

\section{식물구계학적 특정식물}

제주도에 분포하는 것으로 확인한 수생 및 습지식물에 서 식물구계학적 특정식물을 파악하였다. 그 결과 $\mathrm{V}$ 등급 이 10 분류군, IV등급이 7 분류군, III등급이 15 분류군, II등 급이 5 분류군, I등급이 7 분류군 등 총 44 분류군의 식물구 계학적 특정식물이 확인되었다(Table 5).

\section{귀화식물}

조사한 총 52과 98속 181종 6변종 2품종 189분류군에서 귀화식물을 조사하였다. 관상용으로 식재되는 물양귀비 [Hydrocleys nymphoides (Willd.) Buchenau]와 물칸나(Thalia dealbata Fraser ex Roscoe)를 포함하여 귀화식물은 8과 9속 9 종 1 변종 총 10 분류군으로 나타났다(Table 6). 이는 조사 된 수생 및 습지식물 188 분류군에서 $5.32 \%$ 에 해당하는 수 치이다. 귀화식물은 인가 주변의 새로 축조된 인공습지에 주로 생육하고 있었다. 특히 서부지역의 저수지 및 묵밭 에는 털물참새피와 갈래참새피가 다수 분포하고 있었다. 또한 제주지역에 북미 원산의 물칸나(Thalia dealbata Fraser)가 서부지역 인가 주변 연 재배지에 월동하며 자라 고 있는 것을 처음으로 확인하였다.

\section{제주도 수생 및 습생 식물의 입지 환경 및 분포 특성}

제주도의 습지는 식물종 다양성이 매우 높고, 희귀식물 및 식물지리학적으로 중요한 식물 등이 다수 분포하여 학 술적으로 매우 중요한 지역으로 판단된다.

제주도의 하천지역은 대부분 건천으로 수생식물이 분 포하기에 적합하지 않은 환경조건을 갖추고 있었음을 확 인하였다. 그러나 일부 남부지역의 수량이 풍부한 하천에 서는 가래, 말즘, 석창포 등이 분포하였다. 특히 제주도 동 부지역은 서부에 비해 다수의 습지가 분포하고 있고, 희 귀식물인 순채, 어리연, 제주고사리삼 등도 분포하며 습 지식물의 종다양성이 매우 높게 나타났다. 이는 화산 암 
Table 6. The list of naturalized plants.

\begin{tabular}{lc}
\hline \hline \multicolumn{1}{c}{ Scientific Name } & Korean Name \\
\hline Nasturtium officinale R. Br. & 물냉이 \\
Aster subulatus var. sandwicensis (A. Gray ex H. Mann) A. G. Jones & 큰비짜루국화 \\
Bidens frondosa L. & 미국가막사리 \\
Hydrocleys nymphoides (Willd.) Buchenau & 물양귀비 \\
Wolffia arrhiza (L.) Horkel ex Wimm. & 분개구리밥 \\
Paspalum distichum var. indutum Shinners & 털물참새피 \\
Paspalum distichum L. & 갈래참새피 \\
Thalia dealbata Fraser ex Roscoe & 물칸나 \\
Eichhornia crassipes (Mart.) Solms & 부레옥잠 \\
Iris pseudacorus L. & 노랑꽃창포
\end{tabular}

반이 넓게 분포하고 물웅덩이형 암반습지가 많으며, 특히 소택지형의 내륙습지가 집중되어 다양한 습지 및 수변환 경을 갖는 때문으로 파악된다. 반면 제주 서부의 습지는 묵밭, 저수지, 인공연못 등의 습지로 종다양성이 낮고 단 순한 식물상을 보였다. 그리고 비교적 해발이 높은 지역 에서 나타나는 산지 습지에는 사초과와 골풀과 식물의 비 율이 높게 나타났으며, 특히 1100고지 습지와 숨은물뱅디 등의 고산 습지에는 멸종위기식물인 자주땅귀개의 군락 지가 넓게 분포하고 있는 것으로 확인되었다.

그리고 본 연구를 통해 조사된 습지의 다수가 매립과 쓰 레기 무단투기 등이 빈번하게 이루어지는 것으로 파악되 었다. 이는 습지와 수변환경의 급격한 변화로 이어져 습 지식물이 잘 자랄 수 있는 환경을 저해하는 가장 심각한 요인으로 판단되었다. 과거 생육이 확인되었던 것으로 널 리 알려진 실말과 올미 등은 근래에는 그 분포가 확인되 지 않고 있으며, 대가래, 이삭물수세미 등을 포함한 많은 수생식물은 매우 드물게 확인되고 있었다. 또한 서부 지 역의 습지에서는 귀화식물인 털물참새피 등이 넓은 면적 에 걸쳐 군생하고, 미국가막사리 등이 우점하고 있는 것 으로 파악되어 습지에 자라는 귀화식물에 대한 관리와 모 니터링이 필요할 것으로 생각된다.

제주도에 산재한 습지는 다수이나 매우 규모가 작고 얕 아 수량의 변동이 심하여 환경변화에 매우 취약할 것으로 생각된다. 그러나 그곳에서 출현하는 습지식물은 다양하 고 또한 매우 독특한 분류군들이 분포하고 있는 것으로 파악되었다. 따라서, 이러한 종의 보존을 위해서는 현장 조사결과를 토대로 한 습지평가표를 기획하고 작성하여 보존 우선순위를 결정하고, 이에 따라 정밀학술조사 및 보존수준을 결정하는 것이 바람직할 것으로 판단된다.

\section{사 사}

본 논문은 정부(환경부)의 재원으로 국립생물자원관의 지원을 받아 수행하였습니다(NIBR No. 2014-02-001).

\section{Literature Cited}

Choi, H. K. 1985. A Monograph of vascular hydrophytes in Korea. D. C. Dissertation Seoul National University Graduate School. P. 271. (in Korean)

Hara, H. 1938. Preliminary Report on the Flora of Southern Hidaka, Hokkaido (Yezo). XXXI. Botanical Magazine. 52: 395-402.

Jeju Special Self-Governing Province, Korea. 2014. Jeju Special Self-Governing Province, Korea. Retrieved 15 Dec. 2014, from $<$ http://www.jeju.go.kr/>

Jung, J. D. 2010. Systematic Studies of Genus Scirpus L. sensu lato (Cyperaceae) from Korea. D. C. Dissertation Ajou University Graduate School. (in Korean)

Kitamura, S., G. Murata and T. Koyama. 1964. Coloured Illustrations of Herbaceous Plants of Japan 3 (Monocotyledonea). Hoikusa, Osaka. (in Japanese)

Koo, B. H. 2002. A Study on the classification and mapping methods of wetlands in Korea. D. C. Dissertation Seoul National University Graduate School. (in Korean)

Lee, T. B. 2003. Coloured Flora of Korea. Hyangmunsa, Seoul. (in Korean)

Lee, Y. N. 2006 New Flora of Korea. Gyohaksa, Seoul. (in Korean)

Lee, W. T. 1996. Coloured Standard Illustrations of Korean Plants. Academy Publishing Co., Seoul. (in Korean)

Lim, Y. S. 2010. Distribution Characteristics of Hydrophytes in Korea. D. C. Dissertation Soonchunhyang University Graduate School. (in Korean)

Ministry of Environment, Korea. 2012a. A Guide to the 4th National Natural Environment Research. Ministry of Environment, Korea. Pp. 173-226. (in Korean)

Ministry of Environment, Korea. 2012b. Ordinance to partially revise the Enforcement Regulations for the Protection of Wild 
Fauna and Flora: Ministry of Environment Ordinance No. 457. Retrieved 15 Dec. 2014, from <http://www.me.go.kr/>(in Korean)

Ministry of Environment, Korea. 2014. Ordinance to partially revise the Wetland Conservation Act: Law No. 12525. Retrieved 15 Dec. 2001, from <http://www.me.go.kr/>(in Korean)

Muensher, W. C. 1944. Aquatic plants of the United States. Cornell University. Press, Ithaca and London.

Na, H. R. and H. K. Choi. 2008. short communication : Two unrecorded species of Najas L. (Hydrocharitaceae) from Korean flora: N. orientalis and N. oguraensis. Korean Journal of Plant Taxonomy 39: 107-113. (in Korean)

Na, S. T., H. K. Choi, Y. D. Kim and H. C. Shin. 2008. Taxonomic Identities and Distribution of Utricularia japonica and U. tenuicaulis in Korea. Korean Journal of Plant Taxonomy 38: 111-120. (in Korean)

National Institute of Biological Resources. 2012. Red Data Book of Endangered Vascular Plants in Korea. Econature, Seoul. (in Korean)

Ohtaki, S. and T. Ishido. 1980. Illustrated Japanese Water Plants. Hokuryukan. Tokyo. (in Japanese)
Oh, S. C. 1974. A survey report on the plants lived in ponds in Cheju Island. Jeju National University of Education Journal 4: 93-98. (in Korean)

Oh, Y. C. 2000. Korean Cyperaceae. Sungshin Women's University Press, Seoul. (in Korean)

Park, J. W. 2007. The Genera of Vascular Plants of Korea. Flora of Korea Editorial Committee (ed.). Academy Pub. Co., Seoul.

Park, S. H. 2009. New Illustrations and Photographs of Naturalized Plants of Korea. Ilchokak, Seoul. (in Korean)

Sculthorpe, C. D. 1967. The biology of aquatic vascular plants. Edward Arnold Publishers Ltd., London.

Song, H. S. 2005. Illustrated vascular hydrophyte of Korea Jeju. Pulkkonnamu. Seoul. (in Korean)

Yasuro, K. 1994. Aquatic Plants of Japan. Bun-ichi Sogo Shuppan Co. Tokyo. (in Japanese)

Yu, M. H. 2007. (A) taxonomic study of the Korean Lythraceae. M. S. Dissertation Sungkyunkwan University Graduate School. (in Korean)

Zhin, K. L. 2008. Studies on the Plant Distribution in Weltlands and the Chlorophyll Fluorescence Response of Hydrophytes in Jeju City Area. D. C. Dissertation Cheju National University Graduate School. (in Korean). 
Appendix 1. Floristic list of aquatic and wetland plants in Jeju Island (abbreviation: Hg: hygrophyte, Em: Emergent hydrophytes, Fl: Floating-leaved hydrophytes, Sm: Submerged hydrophytes, Ff: Free-floating hydrophytes, V: fifth grade of floristic regional indicator plants, IV: fourth grade of floristic regional indicator plants, III: third grade of floristic regional indicator plants, II: second grade of floristic regional indicator plants, I: first grade of floristic regional indicator plants, $\mathrm{N}$ : Naturalized plants, $\mathrm{T}$ : Threatened plants)

\section{물부추과 (Isoetaceae)}

1. Isoetes sp. (Em); MMO\& KDH-3615

고사리삼과 (Ophioglossum)

2. Mankyua chejuense B.-Y. Sun, M. H. Kim \& C. H. Kim 제주고 사리삼 $(\mathrm{Hg}, \mathrm{V}, \mathrm{T}) ;$ WTFRC-10007712

네가래과 (Marsileaceae)

3. Marsilea quadrifolia L. 네가래(Em); MMO\&KDH-3845

처녀고사리과 (Thelypteridaceae)

4. Cyclosorus interruptus (Willd.) H. Ito 검은별고사리( $\mathrm{Hg}, \mathrm{IV})$; $M M O \& K D H-1759$

\section{삼백초과 (Saururaceae)}

5. Saururus chinensis (Lour.) Baill. 삼백초 $(\mathrm{Hg}, \mathrm{V}, \mathrm{T})$; $M M O \& K D H-924$

\section{연과 (Nelumbonaceae)}

6. Nelumbo nucifera Gaertn. 연(Fl); MMO\& KDH-3882

수련과 (Nymphaeaceae)

7. Nymphaea tetragona Georgi 수련(Fl); MMO\&KDH-909

어항마름과 (Cabombaceae)

8. Brasenia schreberi J. F. Gmel. 순채(Fl, V, T); $M M O \& K D H-901$ 붕어마름과 (Ceratophyllaceae)

9. Ceratophyllum demersum L. 붕어마름(Sm); $M M O \& K D H-299$

10. Ceratophyllum demersum var. quadrispinum Makino 다섯가시 붕어말 $(\mathrm{Sm}) ; M M O \& K D H-4081$

미나리아재비과 (Ranunculaceae)

11. Ranunculus sceleratus L. 개구리자리(Hg); $M M O \& K D H-3528$

12. Ranunculus grandis var. austrokurilensis (Tatewaki) Hara 북미나리 아재비(Hg); $M M O \& K D H-3652$

13. Ranunculus chinensis Bunge 젓가락나물 $(\mathrm{Hg}) ; M M O \& K D H-278$

14. Ranunculus cantoniensis DC. 털개구리미나리 $(\mathrm{Hg}) ; \mathrm{MMO \& KDH}$ 3589

15. Ranunculus tachiroei Franch. \& Sav. 개구리미나리(Hg);

$M M O \& K D H-3780$

\section{마디풀과 (Polygonaceae)}

16. Polygonum thunbergii Siebold \& Zucc. 고마리(Hg); $M M O \& K D H-$ 3775

17. Polygonum maackianum Regel 나도미꾸리낚시(Hg); MMO\&KDH-4132

18. Polygonum muricatum Meisn. 넓은잎미꾸리낚시 $(\mathrm{Hg}) ; \mathrm{KDH}$ \& KSH-985

19. Polygonum praetermissum Hook. f. 좁은잎미꾸리낚시(Hg); MMO\&KDH-4066

20. Polygonum sagittatum L. 미꾸리낚시(Hg); $M M O \& K D H-1376$

21. Polygonum japonicum Meisn. in DC. 흰꽃여뀌 $(\mathrm{Hg}) ; \mathrm{MMO \& KDH-}$ 4167

22. Polygonum japonicum var. conspicuum Nakai 꽃여 뀌(Hg); $M M O \& K D H-4363$

23. Polygonum taquetii H. Lev. 겨이삭여뀌 $(\mathrm{Hg}, \mathrm{III}) ; S G M \& K D H-1417$ 물별과 (Elatinaceae)

24. Elatine triandra Schkuhr 물별(Em, I); $M M O \& K D H-289$

물레나물과 (Clusiaceae)

25. Hypericum laxum (Blume) Koidz. 좀고추나물 $(\mathrm{Hg}) ; M M O$

\section{$\& K D H-1154$}

26. Triadenum breviflorum (Wall. ex Dyer) Y. Kimura 흰꽃물고추 나물(Em, IV); $M M O \& K D H-1374$

27. Triadenum japonicum (Blume) Makino 물고추나물(Em, III); $M M O \& K D H-1064$

박과 (Cucurbitaceae)

28. Actinostemma lobatum (Maxim.) Maxim. in Franch. \& Sav. 뚜 껑덩굴 $(\mathrm{Hg}, \mathrm{I}) ; M M O \& K D H-3964$

십자화과 (Brassicaceae)

29. Nasturtium officinale R. Br. 물냉이(Em, N); WTFRC-25788

앵초과 (Primulaceae)

30. Lysimachia leucantha Miq. 물까치수염(Hg, III, T); $M M O \& K D H-665$

\section{돌나물과 (Crassulaceae)}

31. Tillaea aquatica L. 대구돌나물 $(\mathrm{Hg}, \mathrm{V}, \mathrm{T}) ; M M O \& K D H-539$

32. Penthorum chinense Pursh 낙지다리(Hg, IV); $M M O \& K D H$ 4163

콩과 (Fabaceae)

33. Aeschynomene indica $\mathrm{L}$. 자귀풀 $(\mathrm{Hg}) ; M M O \& K D H-1161$

개미탑과 (Haloragaceae)

34. Myriophyllum spicatum L. 이삭물수세미(Sm); $S G M \& K D H$ 1459

부처꽃과 (Lythraceae)

35. Lythrum anceps (Koehne) Makino 부처꽃 $(\mathrm{Hg}) ; M M O \& K D H-$ 4054

36. Rotala mexicana var. spruceana (Benth.) Koehne 가는마디꽃 (Hg); SGM\&KDH-1514

37. Rotala indica (Willd.) Koehne 마디꽃(Em); $M M O \& K D H-1349$

마름과 (Trapaceae)

38. Trapa japonica Flerow 마름(Fl); $M M O \& K D H-3600$

바늘꽃과 (Onagraceae)

39. Epilobium pyrricholophum Franch. \& Sav. 바늘꽃 $(\mathrm{Hg})$; $M M O \& K D H-4375$

40. Ludwigia epilobioides Maxim. 여뀌 바늘 $(\mathrm{Hg}) ; S G M \& K D H-$ 1509

41. Ludwigia ovalis Miq. 눈여뀌바늘(Em, III); $M M O \& K D H-4017$ 미나리과 (Apiaceae)

42. Hydrocotyle maritima Honda 선피막이 $(\mathrm{Hg}) ; M M O \& \mathrm{KDH}$ 3634

43. Oenanthe javanica (Blume) DC. 미나리(Em); $M M O \& K D H-$ 4168

44. Sium ninsi L. 감자개 발나물 $(\mathrm{Hg}) ; M M O \& K D H-4272$

45. Sium suave Walter 개 발나물 $(\mathrm{Hg}) ; M M O \& K D H-3941$

조름나물과 (Menyanthaceae)

46. Nymphoides peltata (S. G. Gmel.) Kuntze 노랑어리연(Fl, I); $M M O \& K D H-4032$

47. Nymphoides coreana (H. Lev.) H. Hara 애기어리연(Fl, V, T); SGM\&KDH-2398

48. Nymphoides indica (L.) Kuntze 어리연(Fl, II); MMO\&KDH-1068 박주가리과 (Asclepiadaceae)

49. Cynanchum amplexicaule (Siebold \& Zucc.) Hemsl. 솜아마존 (Hg, III, T); MMO\&KDH-4271

50. Cynanchum nipponicum Matsum. 덩굴박주가리(Hg, III); $S G M \& K D H-925$

꿀풀과 (Lamiaceae)

51. Scutellaria dependens Maxim. 애기골무꽃(Hg, II); $M M O \& K D H-1058$

52. Stachys japonica Miq. 석잠풀 $(\mathrm{Hg}) ; J N U B-006980$

53. Lycopus uniflorus Michx. 털쉽싸리(Hg); $M M O \& K D H-4204$

54. Lycopus ramosissimus (Makino) Makino 개쉽싸리 $(\mathrm{Hg})$; $M M O \& K D H-4119$ 
55. Dysophylla stellata (Lour.) Benth. in Wall. 물꼬리풀(Em, V); MMO\&KDH-1381

56. Dysophylla yatabeana Makino 전주물꼬리풀(Em, V, T); $M M O \& K D H-1063$

별이끼과 (Callitrichaceae)

57. Callitriche palustris L. 물별이끼(Em); $M M O \& K D H-502$ 현삼과 (Scrophulariaceae)

58. Limnophila aromatica (Lam.) Merr. 소엽풀(Hg, III, T); $M M O \& K D H-1362$

59. Limnophila sessiliflora (Vahl) Blume 구와말(Em, III); $M M O \& K D H-1350$

60. Lindernia crustacea (L.) F. Muell. 외풀(Hg); $M M O \& K D H-1223$

61. Lindernia micrantha D. Don 논둑외풀 $(\mathrm{Hg}) ; M M O \& K D H-1352$

62. Lindernia procumbens (Krock.) Borbas 밭둑외풀(Em); $M M O \& K D H-4037$

63. Dopatrium junceum (Roxb.) Buch.-Ham. in Benth. 등에풀 (Em); SGM\&KDH-1318

64. Deinostema violaceum (Maxim.) T. Yamaz. 진땅고추풀(Em); $M M O \& K D H-1358$

65. Veronica peregrina $\mathrm{L}$. 문모초 $(\mathrm{Hg}) ; J N U B-007299$

66. Veronica undulata Wall. in Roxb. 물칭개나물(Em); $M M O \& K D H-285$

쥐꼬리망초과 (Acanthaceae)

67. Hygrophila salicifolia (Vahl) Nees in Wall. 물잎풀(Hg, IV);

$M M O \& K D H-4371$

통발과 (Lentibulariaceae)

68. Utricularia yakusimensis Masam. 자주땅귀개 $(\mathrm{Em}, \mathrm{V}, \mathrm{T})$ MMO\& KSH-1044

69. Utricularia tenuicaulis Miki 참통발(Ff); $M M O \& K D H-4034$ 초롱꽃과 (Campanulaceae)

70. Lobelia chinensis Lour. 수염가래꽃(Em); $M M O \& K D H-672$ 꼭두선이과 (Rubiaceae)

71. Galium trifidum L. 가는네 잎갈퀴 $(\mathrm{Hg}) ; M M O \& K D H-3785$

국화과 (Asteraceae)

72. Adenostemma lavenia (L.) Kuntze 물머위(Hg, IV); $M M O \& K D H-2556$

73. Aster tripolium L. 갯개미취 $(\mathrm{Hg})$; WTFRC-25808

74. Aster subulatus var. sandwicensis (A. Gray ex H. Mann) A.G. Jones 큰비짜루국화 $(\mathrm{Hg}, \mathrm{N}) ; M M O \& K D H-4166$

75. Bidens frondosa L. 미국가막사리 $(\mathrm{Hg}, \mathrm{N}) ; M M O \& K D H-4360$

76. Bidens tripartita L. 가막사리(Hg); $M M O \& K D H-1367$

77. Bidens tripartita var. repens (D. Don) Sherff 눈가막사리(Hg); MMO\&KDH-4205

78. Eclipta prostrata (L.) L. 한련초(Hg); $M M O \& K D H-3995$ 택사과 (Alismataceae)

79. Alisma canaliculatum A. Braun \& C. D. Bouche 택사(Em); $M M O \& K D H-135$

80. Alisma orientale (Sam.) Juz. 질경이택사(Em, III); $M M O \& K D H-4362$

81. Caldesia parnassifolia (Bassi ex L.) Parl. 둥근잎택사(Fl, T); $M M O \& K D H-3943$

82. Sagittaria pygmaea Miq. 올미(Em); JNUB-002152

83. Sagittaria aginashi Makino 보풀(Em, I); SGM\&KDH-2448

84. Hydrocleys nymphoides (Willd.) Buchenau 물양귀비(Ff, N); $M M O \& K D H-4030$

자라풀과 (Hydrocharitaceae)

85. Hydrocharis dubia (Blume) Backer 자라풀(Ff, V); MMO\& KDH-3971

86. Ottelia alismoides (L.) Pers. 물질경이(Sm, II); $M M O \& K D H-$ 4116
87. Blyxa aubertii Rich. 올챙 이자리(Sm, T); JNUB-5729

88. Hydrilla verticillata (L. f.) Royle 검정 말 $(\mathrm{Sm}) ; M M O \& K D H$ 916

지채과 (Juncaginaceae)

89. Triglochin maritimum L. 지채(Em); $M M O \& K D H-4376$

가래과 (Potamogetonaceae)

90. Potamogeton pectinatus L. 솔잎가래(Sm, III, T); SGM\&KDH1309

91. Potamogeton maackianus A. Benn. 새우가래(Sm, III); $M M O \& K D H-4082-1$

92. Potamogeton crispus L. 말즘 $(\mathrm{Sm}) ; M M O \& K D H-3922$

93. Potamogeton pusillus L. 실말 $(\mathrm{Sm}) ; J N U B-002334$

94. Potamogeton cristatus Regel \& Maack 가는가래(Fl, I); MMO\& KDH-3897

95. Potamogeton distinctus A. Benn. 가래(Fl); $M M O \& K D H-510$ 96. Potamogeton malaianus Miq. 대가래(Sm); SGM\&KDH-1453 줄말과 (Ruppiaceae)

97. Ruppia maritima L. 줄말(Sm, I); MMO\&KDH-1414

나자스말과 (Najadaceae)

98. Najas gracillima (A. Braun ex Engelm.) Magnus 실나자스말 (Sm); MMO\&KDH-3918

99. Najas graminea Delile 나자스말 $(\mathrm{Sm}) ; M M O \& K D H-3768$ 100. Najas minor All. 톱니나자스말Sm); $M M O \& K D H-4002$ 거머리말과 (Zosteraceae)

101. Zostera marina L. 거머리 말(Sm); KJC\&GYH-4246 창포과 (Acoraceae)

102. Acorus calamus $\mathrm{L}$. 창포 $(\mathrm{Em}) ; M M O \& K D H-683$

103. Acorus gramineus Aiton 석창포(Em, II); $M M O \& K D H-3913$ 개구리밥과 (Lemnaceae)

104. Spirodela polyrhiza (L.) Schleid. 개구리밥(Ff); $M M O \& K D H$ 3892

105. Lemna perpusilla Torr. 좀개구리 밥(Ff); $M M O \& K D H-3891$ 106. Wolffia arrhiza (L.) Horkel ex Wimm. 분개구리밥(Ff, N); $M M O \& K D H-4004$

닭의장풀과 (Commelinaceae)

107. Murdannia keisak (Hassk.) Hand.-Mazz. 사마귀풀(Em); $M M O \& K D H-4367$

곡정초과 (Eriocaulaceae)

108. Eriocaulon decemflorum Maxim. 좀개수염(Em); $M M O \& K D H-4211$

109. Eriocaulon cinereum var. sieboldianum (Siebold \& Zucc. ex

Steud.) T. Koyama ex Y. P. Yang. 곡정초(Em); $M M O \& K D H-1386$

110. Eriocaulon hondoense Satake 큰개수염(Em); SGM\&KDH-1322

111. Eriocaulon sikokianum Maxim. 흰개수염(Em); $M M O \& K D H-$ 4224

112. Eriocaulon miquelianum Korn. 개수염(Em); $M M O \& K D H-1359$

113. Eriocaulon atrum Nakai 검정곡정초(Em); $M M O \& K D H-4212$ 골풀과 (Juncaceae)

114. Juncus gracillimus (Buchenau) V. I. Krecz. \& Gontsch. 물골풀 $(\mathrm{Hg}) ; M M O \& K D H-3520$

115. Juncus effusus var. decipiens Buchenau 골풀 $(\mathrm{Hg})$; $M M O \& K D H-3542$

116. Juncus setchuensis var. effusoides Buchenau 푸른갯골풀 $(\mathrm{Hg})$; $M M O \& K D H-3815$

117. Juncus papillosus Franch. \& Sav. 청비녀골풀 $(\mathrm{Hg})$; MMO\& KDH-4198

118. Juncus wallichianus Laharpe 눈비녀골풀 $(\mathrm{Hg}) ; M M O \& K D H-$ 3777

119. Juncus alatus Franch. \& Sav. 날개골풀 $(\mathrm{Hg}) ; M M O \& K D H-$ 3414 
120. Juncus leschenaultii J. Gay ex Laharpe 참비녀골풀 $(\mathrm{Hg})$; $M M O \& K D H-4140$

\section{사초과 (Cyperaceae)}

121. Cladium chinense Nees 층층고랭이(Hg, IV); $S G M \& K D H$ 1528

122. Cyperus serotinus Rottb. 꽃방동산이(Em); SGM\& KDH-1334

123. Cyperus globosus Forssk. 드렁 방동산이 $(\mathrm{Hg}) ; M M O \& K D H-$ 4025

124. Cyperus sanguinolentus $\mathrm{Vahl}$ 방동산이대가리(Hg); $M M O \& K D H-1357$

125. Cyperus difformis L. 알방동산이 $(\mathrm{Hg}) ; M M O \& K D H-3853$

126. Cyperus haspan L. 모기방동산이 $(\mathrm{Hg}) ; M M O \& K D H-3798$

127. Cyperus hakonensis Franch. \& Sav. 병아리방동산이 $(\mathrm{Hg})$; SGM\&KDH-1343

128. Bolboschoenus planiculmis (F. Schmidt) T.V. Egorova 새섬매 자기(Em); $M M O \& K D H-3522$

129. Bolboschoenus fluviatilis (Torr.) Sojak 큰매자기(Em); MMO\&KDH-3601

130. Schoenoplectus nipponicus (Makino) Sojak 물고랭이(Em); MMO\&KDH-914

131. Schoenoplectus tabernaemontani (C. C. Gmel.) Palla 큰고랭 이(Em); $M M O \& K D H-3603$

132. Schoenoplectus triqueter (L.) Palla 세모고랭이(Em); $M M O \& K D H-3518$

133. Schoenoplectiella triangulata (Roxb.) J. Jung \& H.-K. Choi 송 이고랭이(Em); $M M O \& K D H-3888$

134. Schoenoplectiella hotarui (Ohwi) J. Jung \& H.-K. Choi 좀올 챙 이골(Em); $M M O \& K D H-4217$

135. Schoenoplectiella juncoides (Roxb.) Lye 올챙이골(Em); $M M O \& K D H-4039$

136. Scirpus mitsukurianus Makino 솔방울골(Em); SGM\&KDH-1295

137. Fimbristylis autumnalis (L.) Roem. \& Schult. 애기하늘지기 (Hg); MMO\&KDH-1219

138. Fimbristylis complanata for. exaltata T. Koyama 들하늘지기 (Hg); SGM\&KDH-1336

139. Fimbristylis dichotoma (L.) Vahl 하늘지기 $(\mathrm{Hg})$; $M M O \& K D H-1159$

140. Fimbristylis dichotoma for. floribunda (Miq.) Ohwi 남하늘지 기 $(\mathrm{Hg}) ; M M O \& K D H-4181$

141. Fimbristylis dichotoma for. tomentosa (Vahl) Ohwi 털하늘지 기 $(\mathrm{Hg}) ; M M O \& K D H-4021$

142. Fimbristylis diphylloides Makino in Makino \& Nemoto 검정 하늘지기 $(\mathrm{Hg}) ; M M O \& K D H-1198$

143. Fimbristylis ferruginea var. sieboldii (Miq. Ex C. B. Clarke) Ohwi 갯 하늘지기 $(\mathrm{Hg}) ; M M O \& K D H-4187$

144. Fimbristylis miliacea (L.) Vahl 바람하늘지기(Hg); $S G M \& K D H-1510$

145. Fimbristylis tristachya var. subbispicata (Nees \& Meyen) T. Koyama 꼴하늘지기(Hg); $M M O \& K D H-4218$

146. Eleocharis dulcis Trin. ex Hensch. 남방개(Em); $M M O \& K D H-4084$

147. Eleocharis kuroguwai Ohwi 올방개(Em); $M M O \& K D H-4075$

148. Eleocharis acicularis for. longiseta (Svenson) T. Koyama 쇠털골 (Em); $M M O \& K D H-275$

149. Eleocharis wichurae Boeck. 좀네모골(Em); $M M O \& K D H-4221$

150. Eleocharis congesta var. japonica (Miq.) T. Koyama 바늘골 (Em); $M M O \& K D H-4195$

151. Eleocharis congesta var. thermalis (Hulten) T. Koyama 쇠바 늘골(Em); MMO\&KDH-4142

152. Eleocharis attenuata for. laeviseta (Nakai) Hara 참바늘골 (Em); $M M O \& K D H-3409$
153. Eleocharis equisetiformis (Meinsh.) B. Fedtsch. 까락골(Em); $M M O \& K D H-3410$

154. Eleocharis x yezoensis H. Hara 긴바늘골(Em); KDH\& KSH-962.

155. Rhynchospora faberi C. B. Clarke 골풀아재비 $(\mathrm{Hg}) ; M M O \& K S H$ 1006

156. Rhynchospora fujiiana Makino 좀고양이수염( $\mathrm{Hg}) ; \mathrm{MMO \& KDH-}$ 4225

157. Carex dickinsii Franch. \& Sav. 도깨비사초(Hg); $M M O \& K D H-4203$ 158. Carex dimorpholepis Steud. 이삭사초(Hg); $M M O \& K D H-3611$ 159. Carex dispalata Bott ex A. Gray in Perry 삿갓사초 $(\mathrm{Hg})$; $M M O \& K D H-215$

160. Carex maculata Boott 무늬사초(Hg, III); $M M O \& K D H-3606$ 161. Carex maximowiczii Miq. 왕비늘사초 $(\mathrm{Hg}) ; M M O \& K D H-3450$ 162. Carex phacota Spreng. 쥐방울사초(Hg, III); $M M O \& K D H-304$ 163. Carex scabrifolia Steud. 천일사초(Hg); $M M O \& K D H-3285$ 벼과 (Poaceae)

164. Phacelurus latifolius (Steud.) Ohwi 모새달(Em, I); MMO\&KDH-3957 165. Sacciolepis indica (L.) Chase 물뚝새(Hg); MMO\&KDH-1378 166. Echinochloa oryzoides (Ard.) Fritsch 논피(Hg); $S G M \& K D H-2462$ 167. Echinochloa utilis Ohwi et Yabuno 피(Hg); $M M O \& K D H-4169$ 168. Echinochloa crusgalli var. echinata (Willd.) Honda 물피 $(\mathrm{Hg})$; $M M O \& K D H-4046$

169. Echinochloa crusgalli (L.) P. Beauv. 돌피 $(\mathrm{Hg}) ; M M O \& K D H-$ 3869

170. Paspalum distichum var. indutum Shinners 털물참새피(Em, N); $M M O \& K D H-4059$

171. Paspalum distichum L. 갈래참새피 $(\mathrm{Em}, \mathrm{N}) ; M M O \& K D H$ 3996

172. Isachne globosa (Thunb.) Kuntze 기장대풀 $(\mathrm{Hg})$; $M M O \& K D H-656$

173. Zizania caduciflora (Turcz. ex Trin.) Hand.-Mazz. 줄(Em); $M M O \& K D H-3974$

174. Leersia oryzoides (L.) Sw. 겨풀 $(\mathrm{Hg}) ; M M O \& K D H-1379$ 175. Puccinellia chinampoensis Ohwi 각시미꾸리광이 $(\mathrm{Hg})$; $M M O \& K D H-3515$

176. Glyceria acutiflora Torr. 육절보리풀(Em, III); $M M O \& K D H-3377$ 177. Beckmannia syzigachne (Steud.) Fernald 개피(Hg); $M M O \& K D H-3379$

178. Polypogon monspeliensis (L.) Desf. 갯쇠돌피(Hg, III); $M M O \& K D H-3526$

179. Calamagrostis epigeios (L.) Roth 산조풀 $(\mathrm{Hg}) ; M M O \& K D H-3708$ 180. Phragmites communis Trin. 갈대(Em); $M M O \& K D H-4180$

\section{흑삼룽과 (Sparganiaceae)}

181. Sparganium fallax Graebn. 남흑삼릉(Em, IV); $M M O \& K D H-902$ 182. Sparganium erectum L. 흑삼릉 (Em, V); $M M O \& K D H-3883$ 부들과 (Typhaceae)

183. Typha angustifolia $\mathrm{L}$. 애기부들(Em); $M M O \& K D H-3786$

184. Typha orientalis C. Presl. 부들(Em); $M M O \& K D H-4056$ 마란타과 (Marantaceae)

185. Thalia dealbata Fraser ex Roscoe 물칸나(Em, N); $M M O \& K D H-3875$

\section{물옥잠과 (Pontederiaceae)}

186. Eichhornia crassipes (Mart.) Solms 부레옥잠(Ff, N);

$Y E Y \& K D H-2174$

187. Monochoria vaginalis var. plantaginea (Roxb.) Solms in A.

$\mathrm{DC} \& \mathrm{C}$. DC. 물달개비(Em); $M M O \& K D H-1354$

붓꽃과 (Iridaceae)

188. Iris ensata var. spontanea (Makino) Nakai 꽃창포(Hg, II); $M M O \& K D H-3582$

189. Iris pseudacorus $\mathrm{L}$. 노랑꽃창포(Em, N); $M M O \& K D H-3393$ 